\title{
Borderline personality disorder: resource utilisation costs in Ireland
}

\author{
J. Bourke ${ }^{1, *}$, A. Murphy ${ }^{1}$, D. Flynn ${ }^{2}$, M. Kells ${ }^{3}$, M. Joyce ${ }^{4}$ and J. Hurley ${ }^{4}$ \\ ${ }^{1}$ Department of Economics, Cork University Business School, University College Cork, Cork, Ireland \\ ${ }^{2}$ Cork Mental Health Services, Cork Kerry Community Healthcare, Health Service Executive, St Finbarr's Hospital, Cork, Ireland \\ ${ }^{3}$ Cork Mental Health Services, Cork Kerry Community Healthcare, Health Service Executive, Inniscarraig House, Western Road, Cork, Ireland \\ ${ }^{4}$ National Suicide Research Foundation, Western Gateway Building, University College Cork, Cork, Ireland
}

\begin{abstract}
Objectives. Borderline personality disorder (BPD) is characterised by recurring crises, hospitalisations, self-harm, suicide attempts, addictions, episodes of depression, anxiety and aggression and lost productivity. The objective of this study is to determine the use of direct health care resources by persons with BPD in Ireland and the corresponding costs.
\end{abstract}

\begin{abstract}
Methods. This prevalence-based micro-costing study was undertaken on a sample of 196 individuals with BPD attending publicly funded mental health services in Ireland. All health care costs were assessed using a resource utilisation questionnaire completed by mental health practitioners. A probabilistic sensitivity analysis, using a Monte Carlo simulation, was performed to examine uncertainty.

Results. Total direct healthcare cost per individual was $€ 10844$ annually (ranging from 5228 to 20609 ). Based on a prevalence of $1 \%$ and an adult population (18-65 years) of 2.87 million, we derived that there were 28725 individuals with BPD in Ireland. Total yearly cost of illness was calculated to be up to €311.5 million.

Conclusions. There is a dearth of data on health care resource use and costs of community mental health services in Ireland. The absence of this data is a considerable constraint to research and decision-making in the area of community mental health services. This paper contributes to the limited literature on resource use and costs in community mental health services in Ireland. The absence of productivity loss data (e.g. absenteeism and presenteeism), non-health care costs (e.g. addiction treatment), and indirect costs (e.g. informal care) from study participants is a limitation of this study.
\end{abstract}

Received 15 December 2017; Revised 21 May 2018; Accepted 31 May 2018; First published online 16 July 2018

Key words: Borderline personality disorder, community settings, cost analysis, public health service.

\section{Introduction}

Borderline personality disorder (BPD) is a mental health diagnosis characterised by a pervasive pattern of instability of interpersonal relationships, self-image, affect, and marked impulsivity (American Psychiatric Association, 2005). BPD is typically characterised by patterns of cognitive, emotional and behavioural dysregulation that often manifests in self-harm and suicidal behaviours (Kuo et al. 2006). BPD can be a lifethreatening mental health condition estimated to be present in $0.7-1 \%$ of the general population (Torgersen et al. 2001; Jackson \& Burgess, 2004; Coid et al. 2006). Individuals with a BPD diagnosis typically exhibit selfharming behaviours, with lifetime rates of $\sim 70 \%$ for acts of self-injury, $80 \%$ for suicide attempts and $10 \%$ for suicide reported. As a result, quality of life is found to be severely impaired in this population (Giesen-Bloo et al. 2006; Palmer et al. 2006).

\footnotetext{
* Address for correspondence: Dr J. Bourke, Department of Economics, Cork University Business School, University College Cork, Cork, T12 T656, Ireland.

(Email: jane.bourke@ucc.ie)
}

Due to the chronic nature of BPD, this client group tend to use health care resources more extensively than individuals with other personality disorders or with major depression (Zanarini et al. 2001; Bender et al. 2006). More frequent and continued use of outpatient and inpatient treatment and high use of prescribed psychotropic medication is reported for persons with BPD (Zanarini et al. 2001; Bender et al. 2006). In addition, there is a strong relationship between BPD and poor occupational functioning (Skodol et al. 2002; Jackson \& Burgess, 2004). Therefore, this client group is characterised by recurring crises, hospitalisations, self-harm, suicide attempts, addictions, episodes of depression, anxiety and aggression and lost productivity, explaining why BPD is considered one of the most expensive mental health disorders (van Asselt et al. 2007; Soeteman et al. 2008).

Recent cost-of-illness (COI) studies of BPD in Spain and the Netherlands report that BPD is associated with high COI, as well as indicating that the composition of costs vary considerably (van Asselt et al. 2007; Soeteman et al. 2008). Although there are variations in the identification of health care and societal costs in 
these studies, it is apparent that national variations in BPD treatment exist. For example, medications accounted for $2 \%$ of total costs in the Netherlands (Soeteman et al. 2008) but 25\% in Spain (Salvador-Carulla et al. 2014). This suggests variations in national treatment strategies, although clinical guidelines for BPD (where they exist) advocate behavioural and community support in preference to hospitalisation and medication (e.g. National Institute for Health and Care Excellence, 2009). Given these variations in practice across jurisdictions, examinations of current practice are required on a country-by-country basis.

By the mid-2000s, procedures for recording epidemiological information about self-harm and suicide in Ireland had advanced (e.g. National Self-Harm Registry Ireland) (Flynn et al. 2018a). However, the national government policy framework for mental health services and the national policy framework for suicide prevention activities are both over 10 years old (Health Service Executive, 2005; Government of Ireland, 2006). While the recent succession policy document for suicide prevention is welcome (Health Service Executive, 2015), it is important that decision-making is informed by economic information, ensuring appropriate allocation of scarce health care resources.

In 2006, the overall total economic and social cost of mental health problems in Ireland was estimated to be over three billion euro (O'Shea \& Kennelly, 2008). However, there is a dearth of condition-specific COI studies on mental health disorders in Ireland, a COI of schizophrenia being a notable exception (Behan et al. 2008). BPD in particular, presents huge challenges for mental health services, and estimates suggest that it features in $11-20 \%$ of clinical presentations to mental health outpatient clinics in Ireland (Government of Ireland, 2006). In addition, it is recognised as the most difficult condition for clinicians to treat (Government of Ireland, 2006). This study provides insight on resource use and costs of treating BPD in mental health services in an Irish context, which is of considerable value in budgetary and service planning.

\section{Methods}

\section{Design}

This is a prevalence-based cost analysis study determining the direct health care costs of treating persons with BPD in Ireland.

\section{Setting}

Ireland's public health service, the Health Service Executive (HSE), has responsibility for delivering all public health services in Ireland. There are four core areas of health service for the Irish population: acute hospitals, social care and disability, mental health and primary care. About $90 \%$ of mental health difficulties are addressed through the primary care system in Ireland, whereas the remaining patients require more specialist care which is accessed through mental health services (McDaid, 2013). This secondary level care for more complex mental health difficulties is delivered through multidisciplinary community mental health teams which offers specialised services for adults, children and adolescents, older people and intellectual disability (Government of Ireland, 2006). Multidisciplinary teams typically comprise of psychiatrists, clinical psychologists, social workers, community mental health nurses and occupational therapists. The secondary health care system was the setting for this study as specialist care for BPD is provided at secondary care level in Ireland.

\section{Data collection and sample}

At present, Ireland lacks an integrated health information system with unique patient identifiers. Therefore, a dedicated resource-use questionnaire was designed to capture the full range of secondary level care services utilised by individuals with BPD to facilitate the micro-costing analysis. While other resource use questionnaires exist (e.g. client socio-demographic and service receipt inventory) and have previously been used in Irish health service studies (Cronin \& Bourke, 2017; Raftery et al. 2017), given that standard BPD care requires such a broad range of services, it was important to capture a full 'census' of services so to speak. In designing the dedicated questionnaire, expert opinion from community mental health practitioners were elicited to ensure the full range of services available nationally were captured.

This study examines the cost of BPD, therefore non-BPD resource use is not collected or required. Information about the following resource use in the treatment of BPD was collected: acute hospital stay; emergency department presentation; ambulance use; number and duration of visits with multidisciplinary team members; type and quantity of medications.

Data on resource utilisation in the treatment of BPD was extracted from participants' clinical files by their lead treating clinician. This minimised recall and reliability issues, which may ensue if relying on selfreported resource utilisation from participants. Extracting data directly from participants' files allows the researchers to be confident that each participants' contact with mental health services (e.g. acute inpatient, outpatient and emergency department) is accurately reported. However, it is necessary to acknowledge that in the absence of an integrated health information system, there may be instances where utilisation is not 
recorded, for example, where participants engage with health services outside their primary health service (e.g. presenting to the Emergency Department in another part of the country).

In total, 196 participants were recruited from nine geographically dispersed adult mental health services (AMHS) in urban and rural settings across the Republic of Ireland. Participants were mental health service users, aged 18-64 years, who had received a diagnosis, or met criteria for a diagnosis of BPD (DSM-IV) or emotionally unstable personality disorder (ICD-10). This paper is part of a larger study examining the effectiveness and cost-effectiveness of dialectical behaviour therapy (DBT) for treating individuals with BPD. The participants in this study include all recruited participants at baseline (see Flynn et al. $2018 b$ for study protocol). ${ }^{1}$ Data collection occurred between February 2014 and March 2016. Participants in this study were recruited from secondary care services at multiple geographically dispersed sites across the Republic of Ireland. This sample is representative of the most complex individuals with a formal diagnosis and availing of specialist services. Therefore, the sample accurately depicts the potential costs to the health service if all individuals with a formal diagnosis were actively engaging with secondary level care.

Of the 196 participants, $81 \%$ were female. Ages ranged from 18 to 64 , with $30 \%$ and $29 \%$ of participants in the 35-44 and 25-34 age categories, respectively. In all, $44 \%$ of participants were single; $18 \%$ married; $23 \%$ in a relationship and the remainder were divorced, separated or did not specify marital status. In all, $21 \%$ of participants were in full or part-time employment, with the remainder being unemployed, retired or in education (see Table 1).

\section{Cost analysis}

Following Larg \& Moss (2011) and Drummond et al. (2015), a micro-costing approach employing standard methods was used to estimate the cost of treating BPD. Owing to the lack of national unit cost data/Ready Reckoner for community mental health services, a micro-costing approach was necessary. In undertaking the analysis, national guidelines for conducting cost analyses were adhered to (Health Information and Quality Authority, 2014). The resources used were identified and measured from the resource use questionnaire discussed above. The primary perspective taken was that of the health service provider and payerthe HSE, and included direct health care costs only.

\footnotetext{
${ }^{1}$ While the study protocol refers to both adult and child/adolescent community health services users (Flynn et al. 2018a), this study pertains to AMHS service users.
}

Table 1. Characteristics of study sample

\begin{tabular}{lcc}
\hline Characteristics & $n$ & $\%$ \\
\hline Gender & & \\
$\quad$ Female & 158 & 81 \\
$\quad$ Male & 38 & 19 \\
Age & & \\
18-24 years & 41 & 21 \\
25-34 years & 57 & 29 \\
35-44 years & 58 & 30 \\
45-54 years & 35 & 18 \\
55-64 years & 4 & 2 \\
$\quad$ Did not specify & 1 & 1 \\
Marital status & & \\
Single & 86 & 44 \\
In a relationship & 45 & 23 \\
Married & 36 & 18 \\
Separated/divorced & 27 & 14 \\
Other & 2 & 1 \\
Employment status & & \\
Full-time employment & 23 & 12 \\
Part-time employment & 18 & 9 \\
Student & 20 & 10 \\
Retired & 3 & 2 \\
Unemployed & 90 & 46 \\
Other & 42 & 21 \\
\hline & & \\
& &
\end{tabular}

$n=196$. The study population includes individuals $18-64$ years.

Three categories of direct health care costs were considered: acute care, community care and medication.

To value health resource use, a variety of methods were employed in line with national guidelines (Health Information and Quality Authority, 2014). Diagnosticrelated group (DRG) estimates from the National Ready Reckoner were employed to estimate the costs of acute care (emergency department and acute hospitalisation) (Health Service Executive, 2013a). In order to value the cost of ambulance transfers, an estimate from the literature was employed and adjusted for inflation (Gannon et al. 2007).

Data on number and duration of visits to AMHS were provided in the resource use questionnaire. Using the hourly wage for each professional the value of community care services was estimated. Hourly wages were estimated using national guidelines (Health Information and Quality Authority, 2014), whereby the median value from the salary scales is adjusted for relevant costs including overheads. In the absence of evidence on professionals' administration/ non-patient contact time associated with service delivery, it is assumed these are accounted for in the included overheads (25\%).

With regards to valuing medications, the resource use questionnaire provided data on type and quantity 
of medications, used. To estimate cost of medications national guidelines were employed (National Centre for Pharmacoeconomics, 2016). The price to the wholesaler was extracted from the national medicine database (Primary Care Reimbursement Service, 2017); and the dispensing fee and rebate to the wholesaler were estimated.

The resource use questionnaire provided evidence on resource utilisation for a 6-month period. Assuming this 6 months reflected usual practice, it was directly extrapolated to 12 months to represent annual utilisation.

\section{Sensitivity analysis}

In this analysis, resource estimates are from a sample of data, thus the parameters are subject to uncertainty (Briggs et al. 2006). To address this parameter uncertainty a probabilistic sensitivity analysis (PSA) was employed. This required characterising uncertainty in input parameters, propagating uncertainty through the model using a Monte Carlo simulation model and presenting the implications of parameter uncertainty on the cost estimates. Thus we can examine if uncertainty in the input parameters results in uncertainty surrounding the cost estimate. The latter is illustrated in the 95 percentile ranges presented.

One-way sensitivity analyses are also employed to estimate the burden of BPD to the Irish health service by varying prevalence rates. Prevalence rates of BPD in the population aged 18-65 [as advocated by Torgersen $e t$ al. (2001)] were varied between $0.7 \%$ and $1 \%$, in line with international literature (Torgersen et al. 2001; Jackson \& Burgess, 2004; Coid et al. 2006).

\section{Results}

\section{Direct health service costs}

Acute health services utilised included emergency department attendance, ambulance transfer and inpatient admission. Analysis of the data revealed $45 \%$ of the sample visited the emergency department 2.3 times in a 6 monthly period on average. Applying the relevant costs, the average annual cost of emergency department visits is $€ 717$ per person with BPD. Approximately $18 \%$ of these visits included transfer by ambulance, at a cost of $€ 81$ per person with BPD. The data revealed that $37 \%$ of the sample population were admitted as an inpatient. Applying the relevant DRG tariff, this is valued at the annual average cost per person with BPD of $€ 5497$ for inpatient care (see Table 2).

All persons in the sample utilised AMHS at an annual average cost of $€ 3282$ per person with BPD. These services included psychiatrists, hospital physicians, nursing personnel, clinical psychologists, counsellors, therapists and social workers (see Table 3).
Table 2. Average annual cost of borderline personality disorder per person in Ireland

\begin{tabular}{lrrrr}
\hline $\begin{array}{l}\text { Direct health } \\
\text { care costs }\end{array}$ & $\begin{array}{c}\text { Annual } \\
€\end{array}$ & $\begin{array}{c}\% \text { of } \\
\text { costs }\end{array}$ & $\begin{array}{c}95 \text { percentile } \\
\text { range }^{\mathrm{a}}\end{array}$ & \\
\hline $\begin{array}{l}\text { Acute care } \\
\quad \text { Emergency } \\
\quad \text { department }\end{array}$ & 717 & 7 & 0 & 10481 \\
$\quad \begin{array}{l}\text { Ambulance } \\
\quad \text { Hospitalisations }\end{array}$ & 5497 & 51 & 17 & 31418 \\
$\begin{array}{l}\text { Adult mental health } \\
\text { services }\end{array}$ & 3282 & 30 & 2852 & 3434 \\
$\begin{array}{l}\text { Medication } \\
\text { Total }\end{array}$ & 1267 & 12 & 436 & 2036 \\
\hline
\end{tabular}

${ }^{a}$ Results of probability sensitivity analysis. Beta distribution applied to probability of attending or using each services; gamma distribution applied to the frequency and duration of visits and normal distributions applied to costs.

${ }^{\mathrm{b}}$ See Table 3 for further detail on adult mental health services.

The resource use questionnaire also included questions on type and dosage of medications. $82 \%$ of the sample population reported taking at least one medication. The annual average cost of medications per person with BPD was $€ 1267$. As many persons with BPD may have a means-tested medical card [permitting them access to medication for a $€ 2.50$ fee per item dispensed up to maximum of $€ 25$ at the time of the analysis (Health Service Executive, 2013b)], reimbursement for these medications would be included in HSE budgets, thus are included in the analysis.

The average total cost to the HSE when utilisation of acute health services, AMHS, other funded mental health services and medications are included is $€ 10844$ per person per year. The breakdown of these costs reveals that admissions account for $51 \%$ of the total direct health care costs; mental health services $30 \%$ and medications $12 \%$. Emergency department visits and ambulance transfers account for $8 \%$ collectively (Table 2 ).

\section{Sensitivity analysis}

Within the PSA, a Monte Carlo simulation was conducted around the total cost estimate to account for uncertainty. The sensitivity analysis results indicate a 95 percentile range for the average total costs of $€ 5228$ to $€ 20609$ suggesting uncertainty in the input parameters translates to uncertainty surrounding the cost estimate (see Table 2).

\section{Prevalence}

Table 4 presents the estimated costs of providing health care for the BPD population using the previously 
Table 3. Utilisation of adult mental health services by individuals with borderline personality disorder

\begin{tabular}{|c|c|c|c|c|c|}
\hline & \multirow[b]{2}{*}{ Probability $^{\mathrm{a}}$} & \multicolumn{2}{|c|}{ Frequency $^{\mathrm{b}}$} & \multicolumn{2}{|c|}{ Duration $(h)^{c}$} \\
\hline & & Average & S.D. & Average & S.D. \\
\hline Consultant psychiatrist & 0.80 & 5.09 & 5.70 & 0.41 & 0.21 \\
\hline Senior house officer & 0.27 & 4.51 & 7.17 & 0.50 & 0.30 \\
\hline Staff nurse & 0.22 & 9.23 & 12.85 & 0.59 & 0.29 \\
\hline Social worker & 0.18 & 4.45 & 5.31 & 0.90 & 0.30 \\
\hline Clinical psychologist & 0.17 & 9.89 & 10.15 & 1.12 & 0.48 \\
\hline Registrar psychiatrist & 0.15 & 5.96 & 7.57 & 0.34 & 0.12 \\
\hline Clinical nurse specialist & 0.15 & 12.19 & 12.21 & 0.93 & 0.36 \\
\hline Senior occupational therapist & 0.14 & 12.18 & 25.72 & 0.91 & 0.21 \\
\hline Occupational therapist & 0.14 & 7.68 & 8.78 & 0.92 & 0.46 \\
\hline Senior clinical psychologist & 0.13 & 6.41 & 5.72 & 0.97 & 0.21 \\
\hline Senior registrar psychiatrist & 0.11 & 3.63 & 3.82 & 0.46 & 0.22 \\
\hline Clinical nurse manager & 0.11 & 7.05 & 6.69 & 0.67 & 0.44 \\
\hline Community mental health nurse & 0.11 & 15.24 & 15.72 & 0.49 & 0.22 \\
\hline Addiction counsellor & 0.10 & 11.03 & 7.41 & 0.80 & 0.18 \\
\hline Crisis nurse & 0.08 & 6.93 & 3.43 & 1.26 & 0.40 \\
\hline Senior staff nurse & 0.07 & 21.08 & 25.91 & 0.48 & 0.23 \\
\hline NCHD & 0.06 & 5.50 & 5.73 & 0.43 & 0.24 \\
\hline DSH liaison nurse & 0.04 & 1.71 & 1.25 & 0.89 & 0.39 \\
\hline Family therapist & 0.04 & 9.00 & 8.08 & 1.00 & - \\
\hline Principal clinical psychologist & 0.03 & 1.00 & - & 1.00 & 0.44 \\
\hline DSH nurse & 0.02 & 5.33 & 2.52 & 1.17 & 0.29 \\
\hline Counsellor & 0.02 & 15.67 & 8.50 & 0.89 & 0.10 \\
\hline Alcohol counsellor & 0.02 & 3.00 & 1.41 & 0.92 & 0.12 \\
\hline CBT therapist & 0.02 & 8.00 & 2.00 & 0.94 & 0.10 \\
\hline Team lead social worker & 0.02 & 4.00 & 2.65 & 0.83 & 0.29 \\
\hline HBTT nurse & 0.01 & 4.00 & - & 0.75 & - \\
\hline A\&E SH nurse & 0.01 & 2.00 & - & 0.33 & - \\
\hline Scan nurse & 0.01 & 1.50 & 0.71 & 1.00 & - \\
\hline Trainee psychologist & 0.01 & 3.00 & - & 1.67 & - \\
\hline Assistant psychologist & 0.01 & 3.00 & - & 2.00 & - \\
\hline Social care worker & 0.01 & 3.50 & 3.54 & 1.00 & - \\
\hline Family support worker & 0.01 & 3.00 & 1.41 & 2.00 & - \\
\hline
\end{tabular}

NCHD, non-consultant hospital doctor; DSH, deliberate self-harm; HBTT, home-based treatment team; A\&E: accident and emergency; CBT, cognitive behavioural therapy; $\mathrm{SH}$, self-harm.

a The probability of a client attending professional.

${ }^{\mathrm{b}}$ The number of visits to that professional in a 6 monthly period per client

${ }^{\mathrm{c}}$ The duration per visit, measured in hours per client.

Table 4. Total costs ( $€$ millions) of borderline personality disorder $(B P D)$ in Ireland

\begin{tabular}{lcc}
\hline Prevalence & $\begin{array}{c}\text { Estimate of persons } \\
\text { with BPD }\end{array}$ & $\begin{array}{c}\text { Total health care } \\
\text { costs }(€ \text { million })\end{array}$ \\
\hline $0.7 \%$ & 20108 & 218.05 \\
$1 \%$ & 28725 & 311.50 \\
\hline
\end{tabular}

${ }^{\mathrm{a}}$ Irish adult population aged 18-65: 2.87 million.

discussed range of prevalence rates. With a $1 \%$ prevalence rate the annual cost of treating BPD in Ireland is $€ 311.50$ million in direct health care costs. Lowering the prevalence rate to $0.7 \%$ (one-way sensitivity analysis) decreases the estimated annual direct health care costs to $€ 218.05$ million. These COI estimates assume that all persons with BPD are utilising the mental health services. It is important to note that given the complexity of BPD, persons with the condition may not yet be diagnosed, while others with a diagnosis may not be engaging with the mental health services.

\section{Discussion}

The aim of this study was to estimate the direct health care costs of BPD in Ireland. The results of the analysis 
reveal that the total direct health care cost to the HSE for providing care to a BPD patient is $€ 10844$ annually. An examination of the breakdown of the total cost of care to the health care provider reveals that hospitalisations account for almost half (51\%), and mental health services (AMHS) for almost a third $(30 \%)$ of direct health care costs. The remainder of costs comprise emergency and ambulatory care ( $8 \%$ ) and medication (12\%).

It is important to emphasise again that the perspective of this study is quite narrow, in that only direct health care costs for persons with BPD in Ireland are addressed. For instance, other relevant costs such as those outside (mental) health care like productivity costs of the patients and of informal care are not considered in our analysis. Furthermore, it should also be noted that the overall COI estimates are calculated on the assumption that all individuals aged 18-65 with BPD are engaging with the health services. However, given the complexities of this condition it is likely that many individuals have yet to be diagnosed, some do not engage with services, while others may be attending primary care practitioners. This is no doubt a major limitation of this type of research, and suggests that the costs reported in this paper be treated with a degree of caution. In addition, data on resource use where participants engage with mental health services outside their primary service is not captured in this study, potentially underestimating BPD treatment costs. It is also important to acknowledge that it is not only people with a formal diagnosis of BPD that generate costs to the health system. A recent paper on prevalence rates of BPD symptoms reports that patients with subthreshold BPD are intensive users of health resources (ten Have et al. 2016). Furthermore, in extrapolating from 6 to 12 months to estimate annual resource utilisation, we do not account for seasonality or other factors, which may result in over or under estimating costs.

A strength of this study lies in the data collection methods. Rather than relying on self-reported resource utilisation from participants, data were extracted from participants' clinical files by their lead treating clinician. It is unlikely that study participants would be able to reliably provide information retrospectively about resource utilisation given that individuals with a BPD diagnosis may have multiple service contacts in any 1 week (Zanarini et al. 2001; Bender et al. 2006), and the study period spans across a 6-month timeframe. Data in the clinical file is factual information based on each individual's contact with mental health services (acute inpatient, outpatient and emergency department). As this study examines the cost of BPD only (excludes other unrelated resource use), the lead clinicians are best placed to accurately report on mental health services resource use in the absence of a national integrated health information system. This approach increases the reliability and verifiability of the data, which in turn improves the accuracy of the analysis.

In Ireland, there is a dearth of unit cost data. While hospital admissions are covered by case-mix, there is no accurate unit cost data for community mental health services. The absence of this data is a considerable constraint to research and decision-making in the area of community mental health services in Ireland. This paper contributes to the limited literature in Ireland on resource use and costs in community mental health services.

There can be considerable inconsistencies in the way in which COI studies are conducted. In addition, some studies are far from transparent in describing the data employed and reporting the analysis undertaken. These shortcomings limit the usefulness and comparability of COI studies. To overcome these limitations, we follow guidelines from Larg \& Moss (2011) in reporting and evaluating COI studies. These guidelines provide a standardised appraisal tool which encourages greater transparency of reporting.

While there is an absence of COI studies of BPD in Ireland, previous COI studies for BPD across Europe reported average total costs ranging from $€ 11308$ in Spain to $€ 16852$ in the Netherlands (van Asselt et al. 2007; Soeteman et al. 2008; Salvador-Carulla et al. 2014). These studies also included non-health care costs, such as domestic help, addiction treatment, prison and sheltered employment, and indirect costs such as informal care, sick leave and out-of-pocket expenses. As discussed, our analysis focused on direct health care costs. Therefore, comparisons with these Dutch and Spanish studies in respect of direct health care costs only are more appropriate.

Practices for treating BPD vary across jurisdictions. For example, the analysis in the current study reveals that in an Irish setting, hospitalisations consume the most resources, which is similar to the Netherlands (van Asselt et al. 2007), whereas in Spain, spend on medications accounts for the majority of direct health care costs (Salvador-Carulla et al. 2014). The current study reveals that hospitalisation (51\%) and medication $(12 \%)$ account for $63 \%$ of direct health care spend in Ireland. General clinical recommendations for the treatment of BPD such as those advocated by the National Institute for Health and Care Excellence (2009) and the American Psychiatric Association (2005) advise that the primary treatment for BPD is psychotherapy, preferably in outpatient and day care settings, while hospitalisation and medication have a role in symptom management only (Oldham, 2005; National Institute for Health and Care Excellence, 2009; Departament de Salut Generalitat de Catalunya, 2011). The results of the current study, as well as those in other jurisdictions, 
indicate a high proportion of costs for hospitalisation and medication use. Country-specific COI studies for BPD are vital to determine how resources are currently being allocated and whether such resource allocations are in line with best practice treatments for BPD.

COI studies such as the current study can be employed to inform economic evaluations of specific treatments by providing nationally representative evidence on treatment as usual. This is of particular importance in the absence of standard randomised control trials, owing to lack of clinical equipoise between treatment-as-usual and evidence-based treatments. It is envisaged that our findings on the costs of treating BPD can be used alongside studies investigating the effectiveness of evidence-based treatments for BPD, such as DBT, schema therapy, mentalisation based therapy or transference focused psychotherapy (Departament de Salut Generalitat de Catalunya, 2011; Stoffers et al. 2012). DBT is the recommended evidencebased treatment for persons with BPD (Government of Ireland, 2006), and is currently being implemented in Ireland through the National DBT Project (Flynn et al. 2018b). Furthermore, these future studies can then inform the development of national guidelines that promote effective and cost-effective treatments for BPD, and inform budgeting and resource allocation decisions. This can present policy-makers with considerable challenges, particularly when health budgets are allocated between acute hospital services, medications and non-acute services etc., as is the case in Ireland. ${ }^{2}$ This necessitates budget adjustments so as to transfer the savings from acute services and medication budgets to fund the investment required to deliver interventions such as those recommended in mental health services.

\section{Acknowledgements}

The authors thank the clinicians who extracted the data at each of the study sites, without whom this research would not have been possible.

\section{Financial Support}

This research was supported by the National Office for Suicide Prevention, Health Service Executive, Ireland.

\section{Conflicts of Interest}

The authors declare that there are no conflicts of interest to disclose.

\footnotetext{
${ }^{2}$ In Ireland, the allocated budget for mental health for 2016 was $€ 828.6$ million. While acute care and medication account for $63 \%$ of the direct health care costs for BPD treatment, acute care and medication are not included in mental health budget allocations rather acute care and medication budgets.
}

\section{Ethical Standards}

The authors assert that all procedures contributing to this work comply with the ethical standards of the relevant national and institutional committee on human experimentation with the Helsinki Declaration of 1975, as revised in 2008. Ethical approval to carry out this research was received from the following research ethics committees: Cork Research Ethics Committee of the Cork University Teaching Hospitals, Galway Clinical Research Ethics Committee, HSE North East Area Research Ethics Committee, HSE South East Area Research Ethics Committee, Naas General Hospital Ethics Committee and Sligo General Hospital Research Ethics Committee. All participants were provided with detailed information about the research study and data confidentiality. Participation in the study was voluntary and could be withdrawn at any time. All participants signed written informed consent forms as outlined in the study protocol.

\section{References}

American Psychiatric Association (2005). Diagnostic and Statistical Manual of Mental Disorders, Text Revision, 4th edn. American Psychiatric Press: Washington, DC.

Behan C, Kennelly B, O'Callaghen E (2008). The economic cost of schizophrenia in Ireland: a cost of illness study. Irish Journal of Psychological Medicine 25, 80-87.

Bender DS, Skodol AE, Pagano ME, Dyck IR, Grilo CM, Shea MT, Sanislow CA, Zanarini MC, Yen S, McGlashan TH, Gunderson JG (2006). Brief reports: prospective assessment of treatment use by patients with personality disorders. Psychiatric Services 57, 254-257.

Briggs A, Sculpher M, Claxton K (2006). Decision Modelling for Health Economic Evaluation. Oxford University Press: Oxford.

Coid J, Yang M, Tyrer P, Roberts A, Ullrich S (2006). Prevalence and correlates of personality disorder in Great Britain. The British Journal of Psychiatry 188, 423-431.

Cronin J, Bourke J (2017). Value for money? An examination of the relationship between need and cost in intellectual disability services. Health $\mathcal{E}$ Social Care in the Community 25, 1227-1236.

Departament de Salut Generalitat de Catalunya (2011). Guía de práctica clínica sobre trastorno límite de la personalidad. Agencia d'Informacio, Avaluacio i Qualitat en Salut: Barcelona.

Drummond MF, Sculpher MJ, Claxton K, Stoddart GL, Torrance GW (2015). Methods for the Economic Evaluation of Health Care Programmes. Oxford University Press: Oxford.

Flynn D, Kells M, Joyce M (2018a). Implementation in national systems: DBT in an Irish context. In The Oxford Handbook of Dialectical Behaviour Therapy (ed. M. A. Swales), Oxford University Press: Oxford. doi: 10.1093/oxfordhb / 9780198758723.013.57.

Flynn D, Kells M, Joyce M, Suarez C, Gillespie C (2018b). Dialectical behaviour therapy for treating adults and adolescents with emotional and behavioural dysregulation: 
study protocol of a coordinated implementation in a publicly funded health service. BMC Psychiatry 18, 51.

Gannon B, O'Shea E, Hudson E (2007). The Economic Costs of Falls and Fractures in People Aged 65 and Over in Ireland. Technical Report to NCAOP/HSE/DOHC. Irish Centre for Social Gerontology: Galway (http:/ / www.lenus.ie/hse/ handle/10147/76640). Accessed 5 March 2018.

Giesen-Bloo J, van Dyck R, Spinhoven P, van Tilburg W, Dirksen C, van Asselt T, Kremers I, Nadort M, Arntz A (2006). Outpatient psychotherapy for borderline personality disorder: randomized trial of schema-focused therapy vs transference-focused psychotherapy. Archives of General Psychiatry 63, 649-658.

Government of Ireland (2006). A Vision for Change: Report of the Expert Group on Mental Health Policy. Stationery Office: Dublin.

Health Information and Quality Authority (2014). Draft Guidelines for the Retrieval and Interpretation of Economic Evaluations of Health Technologies in Ireland. Health Information and Quality Authority: Dublin. (http:/ / www. hiqa.ie/publications/guidelines-retrieval-andinterpretation-economic-evaluations-health-technologiesireland) Accessed 23 October 2015.

Health Service Executive (2005). Reach Out: National Strategy for Action on Suicide Prevention 2005-2014. Health Service Executive: Dublin.

Health Service Executive (2013a). Ready Reckoner 2013 - Ready Reckoner of Acute Hospital Inpatient and Daycase Activity and Cost (Summarised by DRG) Relating to 2011 Costs and Activity (National casemix programme . Health Service Executive: Dublin.

Health Service Executive (2013b). Medical card prescription charges. (http://www.hse.ie/eng/services/list/1/ schemes/mc/prescriptioncharge) Accessed 7 January 2017.

Health Service Executive (2015). Connecting for Life: Ireland's National Strategy to Reduce Suicide 2015-2010. Health Service Executive: Dublin.

Jackson HJ, Burgess PM (2004). Personality disorders in the community: a report from the Australian national survey of mental health and wellbeing. Social Psychiatry and Psychiatric Epidemiology 35, 531-538.

Kuo JR, Korslund KE, Linehan M (2006). Borderline personality disorder. In: The Handbook of Adult Clinical Psychology: An Evidence-Based Practice Approach (ed. M. McNulty), pp. 897-940. Routledge: London.

Larg A, Moss JR (2011). Cost-of-illness studies. Pharmacoeconomics 29, 653-671.

McDaid S (2013). Recovery...What You Should Expect from a Good Quality Mental Health Service. Mental Health Reform: Dublin.

National Centre for Pharmacoeconomics (2016). Guidelines for Inclusion of Drug Costs in Pharmacoeconomic Evaluations. NCPE: Dublin (http:/ / www.ncpe.ie/wp-content/ uploads/2016/09/Final-Guidelines-for-Inclusion-of-DrugCosts-in-Pharmacoeconomic-Evaluation-v1.16.pdf) Accessed 17 January 2017.

National Institute for Health and Care Excellence (2009). BORDERLINE PERSONALITY DISORDER: treatment and management. In NICE Clinical Guidelines, No. 78. NICE: London.

O'Shea E, Kennelly B (2008). The Economics of Mental Health Care in Ireland. Mental Health Commission: Dublin, Ireland.

Oldham JM (2005). GUIDELINE WATCH: Practice Guideline for the Treatment of Patients with Borderline Personality Disorder. American Psychiatric Association: Arlington, VA. (http:// psychiatryonline.org/pb/assets/raw/sitewide/ practice_guidelines/guidelines/bpd-watch.pdf) Accessed 18 January 2017.

Palmer S, Davidson K, Tyrer P, Gumley A, Tata P, Norrie J, Murray H, Seivewright $\mathbf{H}$ (2006). The cost-effectiveness of cognitive behavior therapy for borderline personality disorder: results from the BOSCOT trial. Journal of Personality Disorders 20, 466-481.

Primary Care Reimbursement Service (2017). Reimbursable Items. (https://www.sspcrs.ie/druglist/pub;JSESSIONID12= Be0m2oA60cxaTiGbuBS2gWc9QLHUvKPB50HhSq27 KAe8a63SoGKM!1461878253!-879939370). Accessed 17 November 2017.

Raftery M, Burke K, Murray N, O'Duinn O, Murray I, Hallahan B (2017). An intensive personalised support approach to treating individuals with psychosis and co-morbid mild intellectual disability. Irish Journal of Psychological Medicine 34, 99-109.

Salvador-Carulla L, Bendeck M, Ferrer M, Andion O, Aragones E, Casas M (2014). Cost of borderline personality disorder in Catalonia (Spain). European Psychiatry 29, 490-497.

Skodol AE, Gunderson JG, McGlashan TH, Dyck IR, Stout RL, Bender DS, Grilo CM, Shea MT, Zanarini MC, Morey LC, Sanislow CA, Oldham JM (2002). Functional impairment in patients with schizotypal, borderline, avoidant, or obsessive-compulsive personality disorder. American Journal of Psychiatry 159, 276-283.

Soeteman DI, van Roijen LH, Verheul R, Busschbach JJ (2008). The economic burden of personality disorders in mental health care. Journal of Clinical Psychiatry 69, 259-265.

Stoffers JM, Vollm BA, Rucker G, Timmer A, Huband N, Lieb K (2012). Psychological therapies for people with borderline personality disorder. Cochrane Database Systematic Review 15, CD005652.

ten Have M, Verheul R, Kaasenbrood A, van Dorsselaer S, Tuithof M, Kleinjan M, de Graaf R (2016). Prevalence rates of borderline personality disorder symptoms: a study based on the Netherlands Mental Health Survey and Incidence Study-2. BMC Psychiatry 16, 249.

Torgersen S, Kringlen E, Cramer V (2001). The prevalence of personality disorders in a community sample. Archives of General Psychiatry 58, 590-596.

van Asselt ADI, Dirksen CD, Arntz A, Severens JL (2007). The cost of borderline personality disorder: societal cost of illness in BPD-patients. European Psychiatry 22, 354-361.

Zanarini MC, Frankenburg FR, Khera GS, Bleichmar J (2001). Treatment histories of borderline inpatients. Comprehensive Psychiatry 42, 144-150. 